\title{
Una biopolítica feminista de la carne: la gestación subro- gada como ejemplo de los vínculos de opresión entre las mujeres y los animales no humanos
}

\author{
A Feminist Biopolitics of Flesh: Surrogate Pregnancy as \\ an Example of the Links between the Oppression \\ of Women and Nonhuman Animals
}

\section{RESUMEN}

Desde diversos paradigmas teóricos, el feminismo examina las distintas discriminaciones entrelazadas (sexismo, racismo, clasismo, capacitismo, homofobia o especismo). Entre éstas, voy a fijarme en este artículo en los vínculos teóricos y prácticos entre la dominación de las mujeres y la de los animales no humanos. Para ello propongo una distinción biopolítica, cuerpo/carne, frente a las oposiciones zoé/bíos (Agamben) o persona/no persona (Esposito). A partir de aquí articularé el esquema de lo que llamaré una biopolítica feminista de la carne para, por una parte, analizar la categoría de carne en su aspecto más negativo y cosificador, examinando la gestación subrogada como ejemplo de una biopolítica de la carne que muestra las semejanzas entre la opresión de las mujeres y la de los animales no humanos. Por otra parte, y a modo de conclusión, plantearé un sentido positivo del concepto de encarnación. Palabras clave: biopolítica feminista, carne, cuerpo, ética animal, gestación subrogada.

\begin{abstract}
From different theoretical paradigms, feminism examines the different interconnected discriminations (sexism, racism, classism, capacitism, homophobia or speciesism). Among these, in this paper I will focus on the theoretical and practical links between the domination of women and that of nonhuman animals. For this I propose a biopolitical distinction, body/ flesh, in opposition to zoé/bíos (Agamben) or person/non-person (Esposito) distinctions. From here on I will articulate the outline of what I will call a feminist biopolitics of flesh to, on the one hand, analyze the category of flesh in its most negative and reifying aspect, examining surrogate pregnancy as an example of a biopolitics of flesh that shows the similarities between the oppression of women and that of nonhuman animals. On the other hand, and as a conclusion, I will pose a positive sense of the concept of incarnation.
\end{abstract}

Keywords: Feminist biopolitics, flesh, body, animal ethics, surrogate pregnancy.

\section{Sumario}

1.- Introducción: entre mujeres y animales no humanos. 2.- Cuerpo/Carne. 3.- Ser un trozo de carne. 4.- De El cuento de la criada a Un mundo feliz. 5.- Hacia una biopolítica feminista de la carne (viva). - Referencias bibliográficas. 


\section{Introducción: entre mujeres y animales no humanos}

Un rasgo que define a la teoría feminista ha sido su preocupación por vincular la dominación que sufren las mujeres con otros modos de dominación, como son el racismo, el clasismo, el capacitismo, la homofobia o el especismo, entre otros. Ya desde la aparición de las primeras reivindicaciones feministas en la Ilustración podemos observar cómo algunas autoras, como es el caso de Olimpe de Gouges, muestran un interés por analizar también la situación de los esclavos negros y las razones de su dominación y explotación (Puleo, 1993: 153). Y Simone de Beauvoir en El segundo sexo relaciona las causas de la discriminación sufrida por las mujeres con las causas del esclavismo, vinculando la lucha de las mujeres por sus derechos con la lucha por la liberación de los esclavos negros (Beauvoir, 1949: 58). Pues bien, entre las múltiples opresiones entrelazadas que examina el feminismo, voy a fijarme en este trabajo en los vínculos entre la opresión de las mujeres y la de los animales no humanos. Aquí también la historia de esta relación es amplia y larga: entre las sufragistas encontramos a muchas de las primeras defensoras de los derechos de los animales, en su condena de las prácticas de vivisección que se llevaban a cabo en laboratorios y universidades (Buettinger, 1997; Rodríguez Carreño, 2012). Algunas de estas mujeres sufragistas incluso llegaron a ser fundadoras de las primeras sociedades protectoras de animales, como Frances Power Cobbe y Caroline Earle White ${ }^{2}$. Y aunque esta vía de exploración teórica permanezca latente durante el siglo $\mathrm{XX}$, va a ser el ecofeminismo quien centrará su análisis de modo prioritario en los vínculos teóricos y prácticos entre la dominación de las mujeres y la dominación de la naturaleza. Y dentro del ecofeminismo, algunas autoras fijarán entre las mujeres y los animales no humanos las relaciones de esta dominación. Tenemos múltiples textos que adoptan esta perspectiva analítica: en el ámbito anglosajón podemos citar los trabajos pioneros de Josephine Donovan (1990, 2006, 2013, 2016), Carol Adams (1990, 1996, 2014, 2017), Lynda Birke (1994), Greta Gaard (2002, 2011), Lori Gruen (1993, 2007), Deborah Slicer (1991), Deane Curtin (1991) o Brian Luke (1992); y en el ámbito de la filosofía en español destacamos las autoras que se han ocupado de la conexión entre el feminismo y el animalismo: Alicia Puleo (2011), Angélica Velasco (2017), Marta González y Jimena Rodríguez (2008), Jimena Rodríguez Carreño (2012, 2016) e Isabel Balza y Francisco Garrido (2016).

Son diversas las cuestiones que explora este paradigma del animalismo ecofeminista. A la hora de pensar los lazos entre el compromiso feminista y la lucha por los derechos de los animales siempre se plantea la cuestión de si el feminismo debe ser necesariamente animalista o si, al mismo tiempo, la ética animal debe ser feminista. Y, desde luego, una de las preguntas y temas más debatidos es la conexión entre el feminismo y el vegetarianismo (Gaard, 2002; Gruen, 2007; Kheel, 2004;

2 Frances Power Cobbe fue fundadora en 1875 de la Sociedad para la Protección de Animales Sujetos a la Vivisección. Caroline Earle White fue cofundadora en 1867 de la Sociedad de Pensilvania para la Prevención de la Crueldad hacia los Animales (PSPCA); fundadora en 1869 de la Sociedad Femenina de Pensilvania para la Prevención de la Crueldad hacia los Animales (WPSPCA); y fundadora en 1883 de la Sociedad Americana contra la Vivisección (AAVS). 
Lucas, 2005; Rodríguez Carreño, 2016). Ya las primeras animalistas sufragistas entendían que su compromiso ético-político incluía adoptar una dieta vegetariana (Leneman, 1997). Y los nexos teóricos y prácticos entre una ontología y ética animal y la teoría crítica feminista implican necesariamente para Carol Adams, una de las primeras teóricas que trabajan en este sentido, la defensa del vegetarianismo. Desde su célebre primer trabajo de 1990 La política sexual de la carne. Una teoría crítica feminista vegetariana, hasta sus últimos artículos (Adams, 2017a; Adams, 2017b), los planteamientos de Adams mantienen esta posición epistemológica y esta obligación moral y política.

De modo que a la hora de explorar las formas comunes de dominación y opresión de las mujeres y de los animales no humanos, la mercantilización de las mujeres y la de los animales va a ser un elemento priorizado en la investigación de la explotación compartida. Siendo así que el síntoma más destacado de la violencia patriarcal contra mujeres y animales es su conversión en meros objetos. En el caso de los animales no humanos, el análisis se centra en la transformación que se hace de los animales en objetos en sus diversas formas y para distintos fines: alimentación humana, vestido, bestias de trabajo u objetos de experimentación. En el caso de las mujeres, además del cariz siempre patriarcal que presenta toda utilización mercantil de las mujeres, se apunta aquí el fenómeno de la prostitución o el de la gestación subrogada, como ejemplos extremos de cosificación.

Pues bien, para examinar el vínculo específico entre la opresión de las mujeres y la de los animales no humanos propongo una distinción biopolítica, cuerpo/carne, frente a las oposiciones biopolíticas zoé/bios propuesta por Giorgio Agamben o la de persona/no persona de Roberto Esposito. A partir de aquí articularé el esquema de lo que llamaré una biopolítica feminista de la carne para, por una parte, analizar la categoría de carne en su aspecto más negativo y cosificador, examinando la gestación subrogada como ejemplo de una biopolítica de la carne que muestra las semejanzas entre la opresión de las mujeres y la de los animales no humanos. Por otra parte, y a modo de conclusión, plantearé un sentido positivo del concepto de encarnación.

\section{Cuerpo/Carne}

La crítica de los paradigmas dualistas en el conocimiento es uno de los ejes en los que se fundamenta la teoría feminista, que al denunciar y deconstruir los esquemas binarios pone de manifiesto las relaciones entre las distintas opresiones. Val Plumwood (1993) tiene claro que el dualismo es el pivote sobre el que se construye la lógica de la colonización patriarcal, y nos ofrece una lista de los elementos claves que, opuestos en una estructura binaria, subyacen y articulan el pensamiento occidental (Plumwood, 1993: 43). Esta serie no exhaustiva recoge la historia de un proceso de dominación en el que se naturalizan el género, la clase y la raza, así como el cuerpo, la animalidad o las emociones. De modo que todo principio asociado con la naturaleza se entenderá como factor degradado y devaluado en el conocimiento y la estructura social. Pues bien, en esta propuesta de Plumwood, las mujeres y los animales aparecen alineados en el mismo lado de esta dicotomía, jun- 
to con la naturaleza, el objeto y la corporalidad, mientras que enfrentados a éstos coloca a la cultura, la razón, el hombre, lo humano y la subjetividad. Está claro que las mujeres, los animales y lo no humano se asocian con la naturaleza pasiva, y que esta asociación ha fundamentado la estructura de dominación que han soportado y compartido como consecuencia de esta lógica patriarcal.

Todas estas oposiciones pueden ser sintetizadas en la distinción ontológica humanista humano/animal, que constituye -en palabras de María Lugones (2010: 743)la jerarquía dicotómica central en la modernidad colonial. Frente a esta distinción humanista de carácter ontológico y esencialista, desde un paradigma biopolítico se han articulado otras oposiciones que revelan de modo más adecuado la relación entre humanos y animales no humanos. Las distinciones biopolíticas de Agamben -bios/zoé- (Agamben, 1995) o la de Esposito -persona/no persona- (Esposito, 2007) permiten desvelar cómo se estructuran los lugares de la dominación y explotación padecida por animales humanos y no humanos. Así, si atendemos a la historia del colonialismo, de la esclavitud y del imperialismo, podemos constatar cómo animales y humanos hemos compartido muchas veces un mismo lado de la ecuación biopolítica, identificándonos con la zoé o la no persona, esto es, el lado de la naturalización, cosificación y desubjetivización. Los esclavos, los animales criados para el consumo, para la experimentación o utilizados como bestias de carga, y las mujeres sometidas y reducidas a mercancía intercambiable hemos ocupado un mismo lado de la dicotomía biopolítica. Mujeres, animales y esclavos hemos sido zoé o no personas ${ }^{3}$. Pero también hemos podido ocupar el otro lado de la ecuación: humanos -hombres y mujeres- que disfrutan de sus derechos como ciudadanos o animales politizados que, como las mascotas, gozan de algunos privilegios civiles, se sitúan del lado del bíos o de la persona. Ya Cary Wolfe recuerda que la distinción humano/ animal es más un recurso discursivo que una designación zoológica (Wolfe, 2013: 10), que se trata más bien de un tipo de dispositivo o aparato -en sentido foucaultiano- que de una característica esencial ${ }^{4}$. La historia de la ignominia común a la que muchos humanos y más animales hemos sido sometidos lo demuestra. En todo caso, está claro que las viejas distinciones ontológicas no recogen de modo adecuado el carácter de los vínculos entre animales humanos y no humanos. Porque las distinciones biopolíticas han desplazado a las oposiciones ontológicas, mostrando ahora su carácter más «arbitrario, móvil, reversible y fluctuante» (Giorgi, 2014: 29). Ambos, animales humanos y no humanos, podemos encontrarnos siendo zoé o no persona, en tanto que mera vida sin ley, pero también siendo bíos y disfrutar así de una existencia social o dentro de la ley. La distinción ontológica esencialista entre humanos y animales ha desdibujado sus barreras y ahora las distinciones biopolíticas enlazan a los animales humanos y no humanos.

Como hemos señalado, a la hora de establecer estos binarismos, el cuerpo ha sido asociado con la naturaleza y así con las mujeres y los animales, dejando a los

3 Esta cuestión la analizamos en otro trabajo (Balza, 2020).

4 No obstante, hay que tener en cuenta la crítica de Adams hacia Wolfe, cuando afirma que éste olvidaría el papel que la categoría de género juega en la percepción de los otros animales y las actitudes especistas en el trato hacia las mujeres (Adams, 2017a: 91). 
varones los significantes relativos a la cultura y lo racional o lo humano. $\mathrm{Y}$, sin embargo, en nuestra tradición filosófico-teológica el cuerpo se distingue de la carne, apareciendo también cuerpo y carne como polos de una dualidad.

Pues bien, lo que aquí quiero explorar es esta distinción biopolítica entre cuerpo y carne. Si bien Plumwood coloca el cuerpo del lado de lo natural, de las mujeres o de lo objetual, en lo que se ha entendido como cuerpo hemos de distinguir dos elementos diversos como son el cuerpo y la carne, de modo tal que la carne se situaría más bien en este lado que ocupan las mujeres, los animales y la naturaleza en la lista de Plumwood, correspondiéndole al cuerpo, más bien, el lado de la cultura y el sujeto. Es entonces la dicotomía que sufre el cuerpo en estos dos aspectos lo que ahora quiero analizar. Para examinar este binarismo me serviré de los trabajos de Esposito (2004), Wolfe $(2008,2013)$ y Merleau-Ponty (1965) sobre el concepto de carne.

Efectivamente, la carne se caracteriza en nuestra tradición filosófica por su aspecto inerte y pasivo, presentándose como objeto intercambiable y mercantilizable. Frente a ésta, el cuerpo adquiere un carácter activo y animado, mostrando un cariz subjetivo. La carne apela a la multiplicidad desestructurada, frente al organismo unitario que el cuerpo es. De ahí que se asocie con la naturaleza, dejando para el cuerpo el terreno de lo político. Además, su condición material ha hecho que la carne se vincule con el significante animal. Todo ello nos conduce a pensar la carne como elemento negativo y humillado, ocupando el polo devaluado de esta división jerárquica y androcéntrica.

No obstante, la carne exhibe su condición plural y dispersa, su multiplicidad primera, lo que nos va a permitir poder interpretarla en dos sentidos. Aunque sea su aspecto más negativo el que ha sido explorado, también la carne puede enseñar un semblante positivo y vivificante. Porque, como veremos, es la propia constitución de la dualidad la que ha hecho posible la asignación de los papeles de carne muerta frente al de cuerpo viviente. Nuestra tradición filosófico-teológica ha estructurado una biopolítica -sólo- negativa de la carne, donde siempre aparece como elemento sufriente y perecedero, como desecho material sin vida. Pero la dispersión salvaje que la carne descubre también posibilita otra biopolítica que sea afirmativa.

Roberto Esposito recuerda la pluralidad natural potencialmente rebelde que manifiesta la carne. $Y$ es esa multiplicidad la que la remite al estado de naturaleza y la coloca en un espacio anterior a la ley que funda lo político. Utilizando los términos del autor, diremos que la carne es lo impolítico. Por su parte, con el cuerpo nos hallamos en el campo de lo político, en tanto que unidad que domestica y doma toda multiplicidad difusa. Y aunque Esposito reconoce, de alguna manera, el potencial subversivo y vivificante de la carne, entiende que sólo hemos conocido el aspecto inmanente y negativo de la encarnación: ese en el que es materia abyecta y existencia sin vida (Esposito, 2004: 255).

En este sentido, distingo dos momentos en la biopolítica negativa de la carne: en un primer momento, nos encontramos con lo que he llamado "producción de carne», lo que remite al proceso ideológico que permite la construcción del con- 
cepto de carne en tanto que materia inerte y, por lo tanto, objeto intercambiable y mercantilizable. Una vez articulado el concepto de carne en tanto que cosa inanimada y pasiva, nos enfrentamos al segundo momento de la biopolítica negativa de la carne: aquél en el que se reduce a un ser vivo a ser mera carne muerta, lo cual significará arrojarlo al estado de naturaleza anterior a la ley y, por lo tanto, apartarlo del terreno de lo político, donde carece de derechos, de consideración moral o de justicia.

Históricamente tenemos muchos ejemplos de este proceso propio de la biopolítica negativa de la carne. Podemos rastrear distintos momentos en los que los animales humanos y no humanos hemos sido reducidos a nuestra corporalidad encarnada, convertidos en meros objetos de consumo, despojados de nuestro carácter subjetivo y animado. Muchos de ellos son síntoma además de la intersección de las opresiones: los circos, los zoos -tanto de animales no humanos como de humanos-, las prisiones, los campos de concentración y de refugiados, las granjas o los mataderos. Así, desde el proceso de domesticación de los animales no humanos hasta los mataderos industriales. O desde el régimen de esclavitud hasta las cámaras de gas. No debemos olvidar que los métodos de domesticación de los animales no humanos, como las técnicas de reproducción, son parejas a las que dominan y explotan sexualmente a las mujeres (Patterson, 2002: 34-35). Porque ser reducido a pura carnalidad significará haber sido equiparado con mera carne que trabaja, que provoca placer, de la que se obtiene alimento, piel y lana para la fabricación de calzado y vestido, e incluso crías para la propagación del linaje. Y estos modos de explotación afectan tanto a animales no humanos como a animales humanos.

No obstante, entiendo que carne puede significar aspectos de la experiencia opuestos; negativamente: lo objetual, el mero desecho; positivamente: lo vivo, lo múltiple, lo impersonal. La carne hermana a los humanos con los animales no humanos en sus dos aspectos: las mujeres son convertidas en carne muerta y consumible, al igual que los animales; pero son también carne viva: potencia de la vida. Por eso, frente al concepto de cuerpo, propongo utilizar el de carne. La carne expresa esos dos aspectos que nos emparentan y vinculan con lo animal: en su lado negativo, objeto y carne mercantilizable, la cara de la dominación patriarcal; pero, en su lado positivo, la carne es potencia subjetivadora y viva.

Pues bien, mi propuesta es que una biopolítica feminista de la carne se distingue porque explora estos dos momentos de producción de carne y reducción del ser vivo a la misma, atendiendo a las distintas opresiones entrelazadas que encuentra. Pero, al mismo tiempo, tras ese trabajo de análisis y deconstrucción del aspecto negativo de la carne, la biopolítica feminista de la carne se define por pensar un modo positivo de la encarnación que, desde un feminismo material, rompa con la dualidad cuerpo/carne. Porque mantener esa dualidad es otro modo de aceptar una ontología patriarcal y especista, donde se interpreta la carne como elemento inerte y pasivo, frente al cuerpo activo. En el último apartado esbozaré cómo puede articularse una biopolítica feminista de la carne. 


\section{Ser un trozo de carne}

El feminismo ha analizado el modo en que la subjetividad de las mujeres y sus cuerpos encarnados han sido identificados con carne objetual y mercantilizable y así reducidas a mera carne cosificada. La fragmentación y desmembración de la naturaleza y el cuerpo en la cultura occidental es una cuestión explorada por el ecofeminismo y comparada con la matanza y el consumo de animales. Ya las sufragistas del siglo XIX asimilaban tanto el despedazamiento de los cuerpos de las mujeres que supone la pornografía, como las prácticas ginecológicas invasoras, al mismo proceso ideológico que implica la vivisección de animales para la experimentación (Donovan, 1990: 367-369). La deformación, desfiguración y laceración que produce carne mercantilizable a partir de cuerpos-carne vivos y animados es asociado por la crítica feminista con el sistema ético-político inherente al patriarcado.

Carol Adams ha examinado de manera extensa esta cuestión. Sus propuestas críticas nos sirven para articular desde el feminismo un análisis biopolítico de la producción de carne para su posterior deconstrucción. Una de las ideas que sugiere es la de referente ausente: "A través de la matanza, los animales se han convertido en referentes ausentes. Los animales, tanto su nombre como su cuerpo, son convertidos en ausentes como animales para existir como carne» (Adams, 1990: 123). Este concepto de Adams nos remite al hecho de que el cuerpo vivo es sustituido por la carne para el alimento y por la piel para fabricar calzado o vestido, de modo tal que el ser vivo que es el animal desaparece y se convierte en un referente ausente. Ya no nos enfrentamos con el animal-individuo, sino con su ser convertido en mera materia para el consumo. De este modo se produce el concepto de carne muerta frente al cuerpo-carne vivo que era el animal. Lo que así se consigue es la ocultación de cualquier atisbo de subjetividad en los animales al pasar a ser sólo carne-materiacosificada. Dejan de ser alguien para ser percibidos como algo.

La idea de referente ausente está vinculada a su noción de una política sexual de la carne, que se cifra en que «La hombría está construida en nuestra cultura, en parte, por el acceso al consumo de carne y el control de otros cuerpos» (Adams, 1990: 46). Con esta asociación entre virilidad y carnismo, Adams vincula la dominación sobre los animales no humanos con la opresión patriarcal sobre las mujeres, compartiendo ambas opresiones un paradigma común. Y en otro texto, la autora vinculará la opresión especista además de con el sexo, con la raza y con la esclavitud (Adams, 2014; Harper, 2011). Todo ello prueba la intersección de las opresiones, que se constituye en síntoma de la política patriarcal.

De modo que comer carne recogerá los significados agrupados en torno a la virilidad, lo cual se configura como una cuestión no de privilegios sino de simbolismo. Adams afirma que este proceso convierte el término carne en un nombre de la explotación de las mujeres, aceptado y asumido desde ambos lados: opresores y feministas lo utilizarán así (Adams, 1990: 137). De hecho, la carne se ha utilizado en nuestra cultura como metáfora de la dominación de las mujeres: desubjetivizar y entender como materia pasiva a un ser vivo es colocarlo del lado humillado del 
binarismo patriarcal: «sentirse como un trozo de carne es ser tratado como un objeto inerte cuando uno es (o fue), de hecho, un ser vivo, sintiente» (Adams, 1990: 149). Como consecuencia, Adams defenderá un vegetarianismo fundamentado en razones ético-políticas. Pero sin olvidar que la crítica al carnismo y su asociación con la violencia que implica la virilidad patriarcal van más allá de la renuncia a una dieta carnívora 5 .

La asociación entre carnismo y violencia viril viene de lejos. Ya Plutarco compara la gula y el afán de cosas superfluas con la voluptuosidad y la lujuria, en tanto que ambas, gula y lujuria, acaban en crueldad e injusticia ${ }^{6}$. Y Derrida también asocia la virilidad patriarcal con la dieta carnívora: «No se trataría solamente de evocar la estructura falogocéntrica del concepto de sujeto, por lo menos su esquema dominante. Yo querría un día demostrar que este esquema implica la virilidad carnívora. Yo hablaría de un carnofalogocentrismo» (Derrida, 2005: 19). El carnofalogocentrismo alude a una estructura patriarcal de dominación especista que abre una brecha abisal entre los humanos y todos los otros animales no humanos. Esta cuestión la examina en su libro El animal que luego estoy si(gui)endo (Derrida, 2006) proponiendo para ello el término carnologocentrismo, pero en la conversación con Jean-Luc Nancy añade a su crítica un matiz patriarcal. Lo cual significa que la autoridad y autonomía que define la subjetividad en nuestra cultura les es reconocida más bien a los varones, en un esquema vertical de dominación en que los hombres dominan a las mujeres, éstas a los animales, y los adultos a los niños; de modo que el sujeto se correspondería con el concepto de virilidad. Y Derrida nos da una idea: cuando hablamos de comer o de devorar nos referimos a algo más que a la dieta. Porque ese algo más que se come no es ya el alimento: dado que es dueño y señor de toda la naturaleza, el sujeto-varón lo devora todo porque puede, porque es signo de su hombría. Plutarco y Derrida aluden a la insaciabilidad como a una cara inherente a la naturaleza de la virilidad. Precisamente, el sujeto identificado con la masculinidad se configura como la imagen del sujeto neoliberal, que todo lo engulle, en una espiral de consumo sin fin, asolando y aniquilando los recursos naturales, lo que va a ser uno de los puntos centrales de la crítica ecofeminista.

La política sexual de la carne analiza y muestra la común estructura biopolítica que comparten, entre otros, animales no humanos y mujeres: ambos, afirma Adams, encuentran un punto de intersección en el referente ausente, cuando atendemos a la violencia sexual y el consumo cárnico (Adams, 1990: 127). Estos dos conceptos: referente ausente y politica sexual de la carne son útiles para elaborar una crítica feminista de la biopolítica negativa de la carne, ya que nos permiten vincular las opresiones especistas a las sexistas y entender cómo se construye el concepto de carne muerta. Pero, como dice Jennifer McWeeny -en su propuesta de elaborar

5 Lo que se compendia en su propuesta de una ética vegana del cuidado (Adams, 2007a).

6 «Y así, como el que es insaciable en la voluptuosidad con las mujeres, y tras haber probado con varias, vagando por aquí y por allá y sin haber saciado todavía su lujuria, al final se deja caer en villanías, que ni siquiera se deben nombrar, así la intemperancia en materia de condumio, desde el momento que va más allá de lo natural y supera el objetivo de la necesidad, se transforma en crueldad y en injusticia, buscando sólo saciar sus apetitos desordenados» (Plutarco, 2008: 31-32). 
una topografía de la carne-, todas somos carne, los animales también, pero no de la misma manera: hay diferencias en la dominación y éstas deben ser analizadas (McWeeny, 2014: 278). Y propone distinguir tres modos de relaciones intercorporales que sirvan para su topografía, como son: el intercambio, la sustitución y la asimetría (McWeeny, 2014: 279).

La opresión patriarcal que es especista y sexista convierte en carne a los animales, pero también produce carne con las mujeres, convirtiendo sus cuerpos vivos en carne inerte para su explotación. Esta violencia viril la encontramos en distintos lugares: violaciones, abuso de pareja, tráfico de mujeres. Veamos ahora un ejemplo: propongo examinar la gestación subrogada desde los conceptos de Adams -referente ausente y política sexual de la carne-, matizándolos con los tres modos de relaciones intercorporales propuestos por McWeeny.

\section{De El cuento de la criada a Un mundo feliz}

El fenómeno del alquiler de úteros, vientres de alquiler, gestación por sustitución o maternidad subrogada, es uno de los ejemplos contemporáneos más feroces de lo que supone la producción de carne, en este caso, humana. Como vamos a mostrar, en la gestación subrogada se reduce el cuerpo y la subjetividad de las mujeres a mera carne productora, reconociéndose tales cuerpos sólo como materia consumible y mercantilizable.

La primera característica de la subrogación es, como señala Ekman, «la exigencia de una madre ausente» (Ekman, 2014: 152). Ello supone que la mujer contratada para gestar y parir el bebé es entendida como "portadora», "proveedora», «maleta», «incubadora» o «madre sustituta» (Ekman, 2014: 172), como «container fetal» (Guerra Palmero, 2018: 43) o como «vasija» (Pateman, 1988: 294) ${ }^{7}$. Si bien en la Antigüedad, las mujeres que daban a luz bebés para otras familias conservaban su estatuto materno (Puleo, 2017: 175), ahora, la insistencia en acotar la maternidad y paternidad del bebé nacido por esta técnica reproductiva a quienes aportan el material genético -óvulos y espermatozoides-, sea propio o comprado a su vez -en el caso de óvulos, espermatozoides y/o embriones comprados a terceros-, hace que aquélla que gesta y pare el bebé sea descartada como madre. Ello como consecuencia de un proceso de abstracción que divide el sujeto en una dualidad: sujeto / objeto, ánima/cuerpo-carne o persona/no persona. Así, las mujeres son cuerpo material productor, meras máquinas de trabajo, frente a su espíritu o alma subjetivadora. En este proceso de reificación de las madres gestantes, «una parte del yo se convierte en "otra cosa" que pertenece a "otra persona"» (Ekman, 2014: 191). Desde luego, esto constituye un claro ejemplo de lo que Adams considera que es el refe-

7 De ahí el título de la campaña contra los vientres de alquiler «No somos vasijas», que se llevó a cabo en España en 2015. Una de sus acciones fue la elaboración del Manifiesto «No somos vasijas. Las mujeres no se pueden alquilar o comprar de manera total o parcial». Alicia Puleo, una de sus firmantes, dice: «El título de este manifiesto hacía referencia a una antigua conceptualización de la madre. Se reivindicaba, así, el estatuto de persona de las mujeres frente a prácticas que implican una nueva reificación» (Puleo, 2017: 167). Esta es la dirección web de la campaña, donde se puede leer el manifiesto: http://nosomosvasijas.eu. 
rente ausente, en tanto que las madres gestantes, tanto su nombre como su cuerpo, son convertidas en ausentes como mujeres para existir como carne. Este proceso de abstracción y cosificación es una operación propia del proceso que hemos llamado «producción de carne»: por lo que las mujeres reducidas a ser carne en su aspecto negativo se convierten en meras productoras de bebés. La identificación de las mujeres con su carne-material y su equiparación con una fábrica de crías humanas es un paso más en el desarrollo del concepto de enajenación por parte del capitalismo en su estadio neoliberal. Como bien señala Ekman, ahora la enajenación es directa, no indirecta, en tanto que las mujeres se extrañan no sólo de la naturaleza y del producto de su trabajo -como en el concepto de enajenación de Marx-, sino también de su propio cuerpo (Ekman, 2014: 193).

Son las mujeres quienes están afectadas por el problema de la subrogación, con lo que el componente genérico de la investigación será fundamental y prioritario. En este sentido, la mayoría de los análisis señalan el fenómeno del alquiler de úteros como una nueva cara del patriarcado: aquélla en la que enseña su lado más radical y $\mathrm{cruel}^{8}$. Ya Pateman anunciaba que el contrato de subrogación constituía la transformación del patriarcado moderno, como una «nueva forma de acceso y de uso de los cuerpos de las mujeres por parte de los varones» (Pateman, 1988: 288), en tanto que ahora los varones se apropiarían incluso de la génesis física de las crías, algo hasta ahora reservado sólo a las mujeres (Pateman, 1988: 295). Para Pateman y Ekman la gestación subrogada es, junto con la prostitución, el caso en que el ocultamiento de la subordinación estructural de las mujeres en el sistema patriarcal es más claro. Ahora bien, esta dependencia patriarcal se había distinguido por su carácter coactivo, lo que parece no servir para analizar fenómenos de sumisión como el de la subrogación.

Para entender las nuevas formas de sometimiento que produce el patriarcado moderno, Alicia Puleo propone el concepto de "patriarcado de consentimiento" (Puleo, 2017: 176), aquél en el que la subordinación se oculta bajo formas aparentes de libertad y autonomía. La libertad a la hora de establecer un contrato implica que los contratantes conocen y están informados de las consecuencias que supone la firma del mismo, lo que en el caso de los contratos de subrogación no se respeta. Los documentos extensos y muchas veces escritos en inglés, idioma no conocido por muchas mujeres donde este negocio es más frecuente, como es el caso de Oriente Próximo y La India (Armanian, 2017; Rojas, 2008; Domínguez, 2018), imposibilitan que la aceptación del contrato se haga en términos de libertad real. Pero además, los contratos de subrogación estipulan la renuncia al derecho a interrumpir el embarazo o a poder quedarse con el bebé; asumir todos los tratamientos y restricciones del cuerpo las 24 horas del día; la dejación de la libertad de movimiento al estar las mujeres recluidas en centros que controlan todo el proceso de gestación; así como la pérdida de la libertad sexual. No hay ejercicio de la autonomía cuando se firma un contrato sin información real y conocimiento adecuado del mismo; como señala Nuño, «los pactos que anulan la libertad no pueden considerarse válidos»

8 No entramos a debatir aquí los argumentos a favor de la gestación subrogada. Para un resumen y discusión de los mismos: Ekman, 2014. 
(Nuño, 2016: 691). Frente a este patriarcado de consentimiento que algunos entienden que es ejercicio de la libertad individual, Balaguer defiende la asunción de un paternalismo estatal, justificado en tanto en cuanto no debemos «considerar constitucionalmente adecuada la posibilidad de legalizar un sometimiento del cuerpo de la mujer a la mercantilización» (Balaguer, 2017: 177).

La gestación subrogada es, sin duda, una de las manifestaciones más claras y paradigmáticas de lo que constituye una política sexual de la carne. Adams afirmaba que una de las peculiaridades de la construcción de la virilidad en nuestra cultura es el control de otros cuerpos; en este caso, la gestación subrogada, se trata de controlar los cuerpos de las mujeres en tanto que reproductoras de la especie. Pero, además de las mujeres, el patriarcado se distingue por apropiarse de otros cuerpos y de la naturaleza. No son por ello casuales las asociaciones y comparaciones que aparecen entre la gestación subrogada y las técnicas de reproducción de los animales no humanos. Se asimilan los centros donde se confinan a estas mujeres en La India con «granjas de mujeres» (Armanian, 2017; Rojas, 2008; Domínguez, 2018), en una clara reminiscencia de las granjas de cría de animales no humanos; o se entiende que las mujeres son vehículos para la reproducción, tal y como sucede con los animales de granja (Ekman, 2014: 171-172); o se compara a las madres gestantes con «una yegua de cría» (Ekman, 2014: 207). Todo ello es síntoma de que las opresiones están entrelazadas, de que los cuerpos de las mujeres y los de los animales son convertidos en carne muerta, materia inerte para su explotación y consumo. Así, el vínculo y la cercanía entre una madre subrogada y un animal explotado para la cría ganadera es más real que la conexión entre esa madre subrogada y la mujer que contrata su cuerpo para obtener un bebé. Para atender a estas diferencias entre mujeres -y entre animales no humanos también- utilizaré los tres modos de relaciones intercorporales propuestos por McWeeny.

Para articular su topografía de la carne McWeeny desarrolla tres modos de relaciones intercorporales: el intercambio, la sustitución y la asimetría. El intercambio supone que los cuerpos son canjeables cuando son alternativamente usados para la misma función; ejemplo de ello son los cuerpos de los trabajadores o los cuerpos de los animales para el consumo de alimentos: lo mismo es una vaca u otra para elaborar la comida. Se pierde aquí el elemento diferenciador o individualizante de los sujetos. La sustitución constituye una clase especial de intercambio: cuando un cuerpo es utilizado de un modo que normalmente es reservado para otro; ejemplo de ello es cuando los niños y niñas o los animales domésticos son víctimas sustitutas de las mujeres en la violencia de género. Ambos, intercambio y sustitución, trascienden un orden simbólico, en tanto que, puntualiza la autora, son intercambios materiales y reales. Ahora bien, cuando los intercambios o sustituciones no son operativos en un contexto dado, aparece la asimetría: ello supone que una línea de intercambio entre dos cuerpos es imposible y es inimaginable. Con la asimetría, los cuerpos son definidos por su distancia, y nos enseña mucho sobre el tipo de sociedad en la que se manifiesta. Ejemplo de ello son la vinculación establecida entre algunos tipos de trabajo y algunos tipos de cuerpos, como la que se da con los trabajadores de los mataderos o en la distribución geográfica de las fábricas de 
vestidos y la de la agricultura. Ello es prueba de que el capitalismo global protege unos cuerpos y explota otros (McWeeny, 2014: 280).

No todos los cuerpos son iguales para el capitalismo, y no todas las opresiones de género o especistas lo son tampoco. Guerra Palmero insiste en la necesidad de un enfoque trasnacional para el análisis de la subrogación, en el que las cuestiones coloniales que afectan a la raza y a la clase social deben ser prioritarias (Guerra Palmero, 2018: 47-48). Por su parte, Puleo analiza el fenómeno del alquiler de úteros como una forma de "extractivismo reproductivo", en tanto que supone una economía de extracción y exportación de bienes del Sur Global (Puleo, 2017: 182). Y Ekman también señala los componentes de clase y raza que dominan la subrogación (Ekman, 2014: 148). Efectivamente, aquí se nos muestra lo que Lugones llama el sistema de género colonial moderno (Lugones, 2008), en tanto que la situación biopolítica de las mujeres del Sur Global y la de las que solicitan sus servicios como madres gestantes son claramente asimétricas. Está claro que los cuerpos de las mujeres de La India, Tailandia, Ucrania, Kazajistán, Georgia o Camboya, que deben prestarse a gestar los bebés, no están en la misma situación que los cuerpos de las mujeres de Europa, Estados Unidos, Japón o Australia que compran sus servicios. Esos cuerpos no son ni intercambiables ni sustituibles. Alguien puede pensar que materialmente es posible que una mujer europea geste un bebé para una mujer pobre de La India. Y así es. Pero como bien señala McWeeny, para que no haya asimetría entre los cuerpos el intercambio o la sustitución debe ser real, no sólo posible lógicamente. Y aquí está claro que no lo es.

Pero además de los componentes de clase y raza, también debemos tener en cuenta la discriminación especista que señala esta explotación. Las madres subrogadas se identifican, como hemos visto, con los animales. Pero tampoco todos los animales son iguales. Las mujeres que son madres sustitutas comparten modos de opresión con los animales domésticos o de granja, en tanto que sufren técnicas de reproducción similares a éstos. Así, podemos decir que son 'granjables' en el sentido de Davis: esto es, que tienen el sistema reproductivo explotable una y otra vez al servicio de los otros y de su propiedad (Davis, 1995) ${ }^{9}$. Existe una clara disimetría

9 En el campo de los xenotrasplantes, se está investigando ahora la posibilidad hacer crecer órganos del cuerpo humano en el interior de cerdos, vacas y otros animales no humanos, mediante el implante de células madre humanas, dando lugar a quimeras, que son animales híbridos que poseen hígados o páncreas humanos, que podrían trasplantarse al cuerpo humano. No se discuten en el artículo las implicaciones éticas derivadas de la explotación extrema de estos animales no humanos para el uso y bienestar humano, en tanto que estas cerdas y vacas son concebidas como mera carne-materia inerte. El planteamiento de cuestiones éticas aparece, no obstante, muy vinculadas con argumentos especistas, donde la posibilidad de cruzar especies animales humanas con las no humanas repugna moralmente al investigador: «Otro escenario que los investigadores desean evitar por razones que pronto quedarán claras es el cruce de animales quiméricos entre sí. Aunque remota, existe la posibilidad de que algunas de las células madre humanas que hemos implantado migren al nicho que da lugar al sistema reproductor, en vez de permanecer en el que genera el órgano deseado. Como resultado obtendríamos animales que producen espermatozoides u óvulos casi idénticos a los de las personas. $\mathrm{Si}$, a continuación, permitimos que estos animales se crucen entre sí, nos podríamos encontrar con la éticamente desastrosa situación en la que dentro de un animal de granja empezara a gestarse un feto humano (resultante de la fecundación de un óvulo porcino humanizado por parte de un espermatozoide humanizado de otro cerdo)» (Izpisúa Belmonte, 2017: 31-32). 
entre las mujeres que compran los servicios y las que se subrogan. Las primeras nunca se pondrían en el lugar de las segundas, y por ello tampoco pueden ser comparadas con los animales.

Esta asimetría que se da entre mujeres de distintos estamentos sociales está muy bien reflejada en El cuento de la criada de Margaret Atwood (1985). La sociedad distópica que retrata coloca en lugares no intercambiables ni sustituibles a las mujeres que engendran los bebés y a las mujeres que pertenecen a la clase dominante. Las primeras son esclavas de las segundas, en tanto que sus cuerpos les pertenecen. Y aunque la opresión de género también afecta a las mujeres mejor situadas en esta sociedad estamental, su situación es más cómoda y menos opresiva. Está claro que las mujeres madres subrogadas se conciben como cuerpos intercambiables, que han perdido toda subjetividad e individualidad. Hasta el punto de que el sueño patriarcal del capitalismo neoliberal sería el de poder sustituirlas por máquinas productoras de niños. Esta fantasía del patriarcado es la que ya imaginó Huxley en Un mundo feliz (Huxley, 1932), donde los bebés son producidos en serie en una fábrica de seres humanos. Aquí los cuerpos-carne de las mujeres ya no son necesarios para la reproducción de la especie. Pero ello no les libra de la dominación patriarcal.

\section{Hacia una biopolítica feminista de la carne (viva)}

Mi propósito en este trabajo era el de articular el esbozo de lo que he llamado una biopolítica feminista de la carne, en la que he distinguido dos momentos. Hasta ahora, he explorado un primer momento de crítica y deconstrucción de un concepto de carne negativo. Para ello he planteado la distinción biopolítica cuerpo/carne, que creo ayuda a entender mejor las opresiones compartidas por mujeres y animales no humanos. Para examinar como se gesta la producción del concepto de carne inerte, he utilizado los conceptos de Adams de referente ausente y de politica sexual de la carne. Asimismo, los tres modos de relaciones intercorporales propuestos por McWeeny -intercambio, sustitución y asimetría-, me han servido para matizar los aspectos coloniales, sexistas y especistas de la explotación patriarcal. Aplicar estos conceptos al análisis de un fenómeno contemporáneo de dominación patriarcal extrema, como es la gestación subrogada, ha ayudado para situar la cuestión.

Queda ahora apuntar cómo es el segundo momento de la biopolítica feminista de la carne, éste en el que debemos pensar un concepto positivo de la encarnación. Si el concepto de carne como materia inerte es inherente a una tradición ontológica patriarcal, humanista y especista, el concepto de carne viviente será propio de la tradición más materialista y feminista de la filosofía. Hay que subrayar que lo que quiero plantear no es una concepción espiritualista de la carne -como lo es en la tradición cristiana-, sino una noción materialista, en tanto que esta carne no «remite al cuerpo traducido a espíritu, o al espíritu introyectado en el cuerpo» (Esposito, 2004: 262). Dicho de otro modo, si como afirma Esposito hay una corporeización de la carne en el cristianismo, yo propongo ahora pensar una encarnación del cuerpo desde el feminismo material ${ }^{10}$. 
Además del feminismo material, un autor como Merleau-Ponty, que representa otra tradición filosófica en la que la carne es algo más que mero receptáculo material inerte, me servirá para articular un concepto vivo de la encarnación. Porque si Merleau-Ponty se dispone a analizar «Lo que llamamos carne, esa masa trabajada por dentro, [que] no tiene nombre en ninguna filosofía» (Merleau-Ponty, 1965: 183), ahora, desde la biopolítica feminista de la carne, pretendemos designar esa carne silenciada, para que esa otra forma de pensar la encarnación se convierta en el «camino para ser en común» (Wolfe, 2013: 50) para los animales humanos y los no humanos.

Frente a una carne inerte y cosificada, el sentido vivo de la carne remite a ese común sustrato compartido por los humanos con otras formas de vida (Wolfe, 2013: 50). Una de las notas que caracterizará entonces a la carne viviente frente a la carne silente y muerta es su trascendencia. A este respecto, el concepto de carne (chair) de Merleau-Ponty abre el cuerpo hacia la exterioridad, frente al movimiento de interiorización y repliegue en sí mismo que implica una noción de carne reificada (Esposito, 2004: 262). Si producir carne en su sentido inerte y pasivo conduce a la inmanencia subjetiva, contemplar la carne viva remite a la trascendencia del sujeto. Y ser trascendente significará poder encontrarse con todo lo vivo. En tanto que materia primera y elemento común de lo viviente, la carne posibilita el despliegue al movimiento de energía exterior, frente a la clausura impermeable del cuerpo.

Por otra parte, una biopolítica de la carne que acentúe el carácter vivo de la encarnación disuelve el dualismo entre cuerpo y carne al insistir en el aspecto encarnado del cuerpo, en tanto que subraya que la carne es agencia animada y no ya objeto reificado. La biopolítica feminista de la carne que quiero articular parte de paradigmas materialistas, lo que supone que no se sitúa en esquemas de pensamiento ontológicos de corte patriarcal, especistas y dualistas. Precisamente, la producción de carne en tanto concepto negativizado ha sido posible como polo de una dualidad entre cuerpo y carne donde ésta ha sido representada como principio pasivo y muerto, frente a un cuerpo activo, subjetivo y vivo.

La biopolítica feminista de la carne descubre otro nexo de contigüidad entre humanos y animales no humanos, alejados ya de la reificación y de la explotación. Por ello permite pensar el vínculo entre mujeres y animales no humanos de otro modo: más allá de la opresión y el dolor en el que ser carne (muerta) ha situado a las mujeres y a los animales, ahora ser carne (viva) abre a una comunidad posible entre humanos y animales no humanos. Y, en este camino, la empatía y la compasión serán sus herramientas. Dejamos para un próximo trabajo su exploración.

\section{REFERENCIAS BIBLIOGRÁFICAS}

Agamben, Giorgio (1995). Homo Sacer. El poder soberano y la nuda vida I, València: Pre-Textos, 1998 (traducción de Antonio Gimeno Cuspinera).

Adams, Carol J. (1990). La política sexual de la carne. Una teoría crítica feminista vegetariana, Madrid: ochodoscuatro ediciones, 2016 (traducción del equipo editorial). 
Adams, Carol J. (1996). «Ecofeminismo y el Consumo de Animales» en WARren, Karen J. (ed.) (1996). Filosofías ecofeministas, Barcelona: Icaria, pp. 195-225.

Adams, Carol J. (2014). «Why a Pig? A Reclining Nude Reveals the Intersections of Race, Sex, Slavery, and Species» en AdAms, Carol J. y Lori GrUEN (eds.) (2014). Ecofeminism: Feminist Intersections with Other Animals and the Earth, New York and London: Bloomsbury, pp. 209-224.

AdAms, Carol J. (2017a). «Proteína feminizada: significado, representaciones e implicancias» en Andreatta, María Marta, Pezzetta, Silvina y Eduardo Rincón (eds.). Crítica y animalidad: cuando el otro aúlla. La Plata: Editorial Latinoamericana Especializada en Estudios Críticos Animales, pp. $72-97$ (traducción de María Marta Andreatta).

Adams, Carol J. (2017b). «The Poetics of Christian Engagement: Living Compassionately in a Sexual Politics of Meat World» en Studies in Christian Ethics, Vol.30, $\mathrm{N}^{\mathrm{o}} 1$, pp. $45-59$.

Armanian, Nazanín (2017). «Vientres de alquiler y mercaderes de bebés en Oriente Próximo» en Público. Disponible en: http://blogs.publico.es/puntoyseguido/3743/vientre-de-alquiler-y-mercaderes-de-bebes-en-el-oriente-proximo (Fecha de consulta: 03/8/18).

Aтwood, Margaret (1985). El cuento de la criada, Barcelona: Seix Barral, 1987 (traducción de Elsa Mateo Blanco).

BALzA, Isabel (2014). «Los feminismos de Spinoza: corporalidad y renaturalización» en Daimon. Revista Internacional de Filosofía, N63, pp. 13-26.

BAlzA, Isabel (2020). «Si esto es una vaca: Feminismo y Biopolítica de la carne» en Ideas y Valores, $\mathrm{N}^{\mathrm{o}} 173$ (en prensa).

BALZA, Isabel y Francisco GARRIDo (2016). «¿Son las mujeres más sensibles a los derechos de los animales? Sobre los vínculos entre el animalismo y el feminismo» en Isegoría. Revista de Filosofía Moral y Política, No54, pp. 289-305.

BAlAguer, Ma Luisa (2017). Hij@s del mercado. La maternidad subrogada en un Estado Social, Madrid: Cátedra.

BeAuvoir, Simone de (1949). El segundo sexo. Volumen I: Los hechos y los mitos, Madrid: Cátedra, 2000 (traducción de Alicia Martorell).

BIRKe, Lynda (1994). Feminism, Animals and Science. The Naming of the Shrew, Buckingham-Philadelphia: Open University Press.

Buettinger, Craig (1997). «Women and Antivivisection in Late Nineteenth-Century America» en Journal of Social History, Vol. 30, Nº, pp. 857-872.

Curtin, Deane (1991). "Toward an Ecological Ethic of Care» en Donovan, Josephine y Carol J. Adams (eds.) (2007). The Feminist Care Tradition in Animal Ethics: a Reader, New York: Columbia University Press, pp. 87-104.

Davis, Karen (1995). «Thinking Like a Chicken: Farm Animals and the Feminine Connection» en Adams, Carol J. y Josephine Donovan (eds.). Animals and Women. Feminist Theoretical Explorations, Durham, N.C.: Duke University Press, pp. 192-212.

DerridA, Jacques (2005). «"Hay que comer bien" o el cálculo del sujeto» en Confines, N¹7. DerridA, Jacques (2006). El animal que luego estoy si(gui)endo, Madrid: Trotta, 2008 (traducción de Cristina de Peretti y Cristina Rodríguez Marciel). 
Domínguez, Teresa (2018). «Vientres de alquiler, la nueva demanda social. Entrevista a Rita Banerji, escritora, activista feminista y fundadora de 50 Million Missing» en Contrainformacion.es. Disponible en: https://contrainformacion.es/vientresalquiler-la-nueva-demanda-social-entrevista-rita-banerji-escritora-activistafeminista-fundadora-50-million-missing/ (Fecha de consulta: 20/7/18).

Donovan, Josephine (1990). «Animal Rights and Feminist Theory» en Signs, Vol.15, $\mathrm{N}^{\mathrm{o}} 2$, pp. 350-375.

Donovan, Josephine (2006). «Feminism and the Treatment of Animals: From Care to Dialogue» en Signs, Vol.31, N'2, pp. 305-330.

Donovan, Josephine (2013). «The Voice of Animals: A Response to Recent French Care Theory in Animal Ethics» en Journal for Critical Animal Studies, Vol.11, No1, pp. 8-23.

Donovan, Josephine (2016). The Aesthetics of Care: On the Literary Treatment of Animals, New York: Bloomsbury Publishing.

EKMAN, Kajsa Ekis (2014). El ser y la mercancía: prostitución, vientres de alquiler y disociación, La Habana: Editorial Cenesex, 2015 (traducción de Adolfo Eduardo Fuentes Garnelo).

Esposito, Roberto (2004). Bíos. Biopolítica y filosofía, Buenos Aires: Amorrortu, 2006 (traducción de Carlo R. Molinari Marotto).

Esposito, Roberto (2007). Tercera persona. Política de la vida y filosofía de lo impersonal, Buenos Aires: Amorrortu, 2009 (traducción de Carlo R. Molinari Marotto).

GAARD, Greta (2002). «Vegetarian Ecofeminism. A review essay» en Frontiers: A Journal of Women Studies, Vol.23, No3, pp. 117-146.

GAARD, Greta (2011). «Ecofeminism Revisited: Rejecting Essentialism and RePlacing Species in a Material Feminist Environmentalism» en Feminist Formations, Vol.23, No2, pp. 26-53.

GiongI, Gabriel (2014). Formas comunes. Animalidad, cultura, biopolítica, Buenos Aires: Eterna Cadencia.

GonzÁlez, Marta y Jimena Rodríguez (2008). «Al margen de los márgenes: encuentros y desencuentros entre feminismo y defensa de los animales» en González, Marta I., Riechmann, Jorge, Rodríguez Carreño, Jimena y TAFAlla, Marta (coords.). Razonar y actuar en defensa de los animales, Madrid: Los Libros de La Catarata, pp. 83-106.

Gruen, Lori (1993). «Dismantling Oppression: An Analysis of the Connection Between Women and Animals» en GAARD, Greta (ed.). Ecofeminism. Women, Animals, Nature, Philadelphia: Temple University Press, pp. 60-90.

Gruen, Lori (2004). «Empathy and Vegetarian Commitments» en DonovaN, Josephine and Carol J. AdAms (eds.) (2007). The Feminist Care Tradition in Animal Ethics: a Reader, New York: Columbia University Press, pp. 333-343.

Guerra Palmero, Ma José (2018). «Contra la mercantilización de los cuerpos de las mujeres. La "gestación subrogada" como nuevo negocio transnacional» en RoDRÍGUEz Delgado, Janet. Vulnerabilidad, justicia y salud global, Dilemata. Revista Internacional de Éticas Aplicadas, No26, pp. 39-51.

Harper, A. Breeze (2011). «Connections: Speciesism, Racism, and Whiteness as the 
Norm» en Kemmerer, Lisa (ed.). Sister Species. Woman, Animals and Social Justice, University of Illinois Press, pp. 72-78.

Huxley, Aldous (1932). Un mundo feliz, Madrid: Debolsillo, 2014 (traducción de Ramón Hernández).

IzPIsúA BELmonte, Juan Carlos (2017). «Órganos humanos fabricados dentro de animales» en Investigación y Ciencia, $\mathrm{N}^{\mathrm{o}}$ de enero, pp. 26-32.

KHEEL, Marti (2004). "Vegetarianism and Ecofeminism: Toppling Patriarchy with a Fork» en SAPONTZIS, Steve F. (ed.). Food for Thought: The Debate Over Eating Meat, Amherst, NY: Prometheus Books, pp. 327-341.

LENEMAN, Leah (1997). "The awakened instinct: vegetarianism and the women's suffrage movement in Britain» en Women's History Review, Vol.6, No2, pp. 271-287.

LucAs, Sheri (2005). «A Defense of the Feminist-Vegetarian Connection» en Hypatia, Vol.20, N¹, pp. 150-177.

Lugones, María (2008). «Colonialidad y Género» en Tabula Rasa, N9, pp. 73-101.

Lugones, María (2010). «Toward a Decolonial Feminism» en Hypatia, Vol.25, N44, pp. 742-759.

LUKE, Brian (1992). «Justice, Caring and Animal Liberation» en DonovaN, Josephine and Carol J. AdAms (eds.) (2007). The Feminist Care Tradition in Animal Ethics: a Reader, New York: Columbia University Press, pp. 125-152.

Merleau-Ponty, Maurice (1965). Lo visible y lo invisible, Barcelona: Seix Barral, 1970 (traducción de José Escudé).

NuÑo Gómez, Laura (2016). «Una nueva cláusula del Contrato Sexual: vientres de alquiler» en Isegoría. Revista de Filosofía Moral y Política, N55, pp. 683-700.

McWeEny, Jennifer (2014). «Topographies of Flesh: Women, Nonhuman Animals, and the Embodiment of Connection and Difference» en Hypatia, Vol.29, No2, pp. 269-286.

PATterson, Charles (2002). ¿Por qué maltratamos tanto a los animales? Un modelo para la masacre de personas en los campos de exterminio nazis, Lleida: Milenio, 2008 (traducción de Ramón Sala Gili).

PAteman, Carole (1988). El contrato sexual, Barcelona: Anthropos, 1995 (traducción de $\mathrm{M}^{\mathrm{a}}$ Luisa Femenías, revisada por Maria-Xosé Agra Romero).

Plumwood, Val (1993). Feminism and the Mastery of Nature, Londres: Routledge.

Plutarco (2008). Acerca de comer carne. Los animales utilizan la razón, Palma de Mallorca: José J. de Olañeta (traducción de Fernando Ortega).

Puleo, Alicia H. (ed.) (1993). La Ilustración olvidada. La polémica de los sexos en el siglo XVIII, Madrid: Anthropos.

Puleo, Alicia H. (2011). Ecofeminismo para otro mundo posible, Madrid: Cátedra.

Puleo, Alicia H. (2017). «Nuevas formas de desigualdad en un mundo globalizado. El alquiler de úteros como extractivismo» en Revista Europea de Derechos Fundamentales, No29, pp. 165-184.

Rodríguez CARreño, Jimena (2012). «Frances Power Cobbe y la lucha contra la vivisección como causa femenina en la Inglaterra del siglo XIX» en RodRíguez CArreño, Jimena (ed.). Animales no humanos entre animales humanos, Madrid: Plaza y Valdés, pp. 85-115. 
Rodríguez CARREÑo, Jimena (2016). «Feminismo y dieta vegetariana: breve exposición de las principales posturas sobre el vínculo entre la subordinación de las mujeres y el consumo de carne» en Revista Latinoamericana de Estudios Críticos Animales, Vol.2, No2, pp. 120-139.

RojAs, Ana Gabriela (2008). «Se alquila vientre en India» en El País. Disponible en: https:/ / elpais.com/diario/2008/08/03/sociedad/1217714403_850215.html. (Fecha de consulta: 04/8/18).

SLICER, Deborah (1991). "Your Daughter or Your Dog? A Feminist Assessment of the Animal Research Issue» en Donovan, Josephine y Carol J. Adams (eds.) (2007). The Feminist Care Tradition in Animal Ethics: a Reader, New York: Columbia University Press, pp. 105-124.

Velasco Sesma, Angélica (2017). La Ética Animal. ¿Una cuestión feminista? Madrid: Cátedra.

Wolfe, Cary (2008). «Flesh and Finitude: Thinking Animals in (Post)Humanist Philosophy» en SubStance, Vol.37, No3, pp. 8-36.

Wolfe, Cary (2013). Before the Law. Humans and Other Animals in a Biopolitical Frame, Chicago: The University of Chicago Press.

Recibido el 25 de marzo de 2018 Aceptado el 15 de mayo de 2018 BIBLID [1132-8231 (2018): 27-44] 